Received: 10.10 .2021

Revised: 10.11 .2021

Accepted: 24.12 .2021

DOI: $10.17804 / 2410-9908.2021 .6 .019-031$

\title{
PRODUCTION OF GRADIENT INTERMETALLIC LAYERS BASED ON ALUMINUM ALLOY AND COPPER BY ELECTRON-BEAM ADDITIVE TECHNOLOGY
}

\author{
A. V. Chumaevsky)*, A. O. Panfilov' ${ }^{\text {b) }}$, E. O. Knyazhev ${ }^{\text {c) }}$, A. P. Zykova ${ }^{\text {d) }}$, A. V. Gusarova ${ }^{\text {e) }}$, \\ K. N. Kalashnikov ${ }^{\text {f) }}$, A. V. Vorontsov ${ }^{\text {g) }}$, N. L. Savchenko ${ }^{\text {i) }}$, S. Yu. Nikonov ${ }^{\text {j) }}$, \\ A. M. Cheremnov ${ }^{\text {k) }}$, V. E. Rubtsov ${ }^{1)}$, and E. A. Kolubaev ${ }^{\mathrm{m})}$ \\ Institute of Strength Physics and Materials Science, Siberian Branch of the Russian Academy of Sciences, \\ 2/4 Akademicheskiy Ave., Tomsk, 634055, Russian Federation

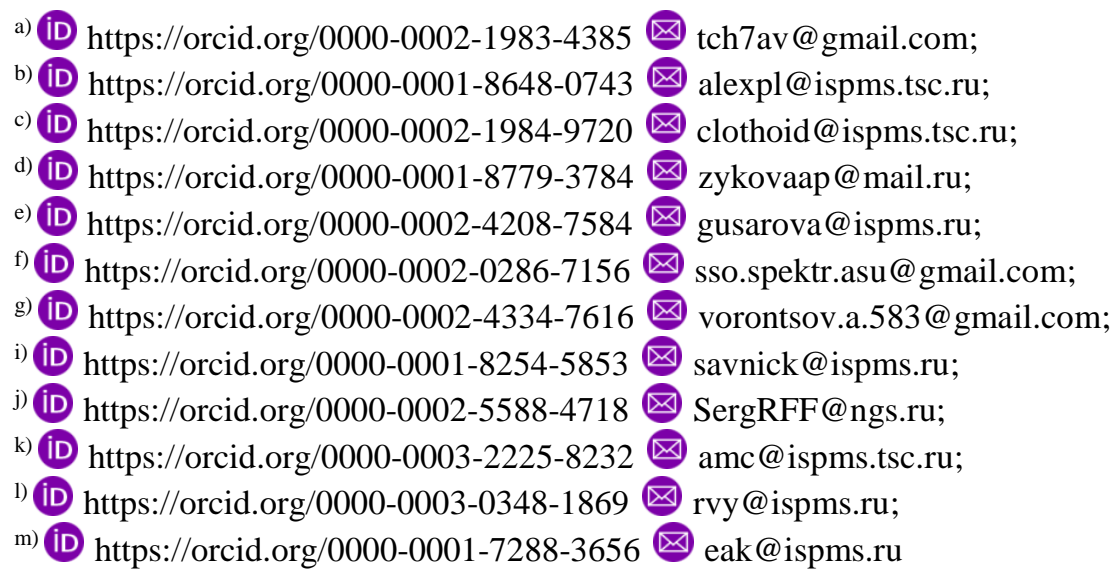 \\ *Corresponding author. E-mail: tch7av@gmail.com \\ Address for correspondence: 634055 Tomsk, Akademicheskiy pr., 2/4, Russian Federation \\ Tel.: 89618914149
}

This study presents the results of experimental work on the production and examination of samples of laminated polymetallic products made by wire-feed electron-beam additive technology using the technique of controlled filament feeding into the melt bath. The structure of the products based on M1 copper and AMg5 aluminum alloy combines metallic and intermetallic layers with the presence of a gradient transition between the phases. Inside the layers with a transition structure the distribution of intermetallic phases can be of different types. The microhardness values of the different structural constituents of the samples differ by more than a factor of 16 . The mechanical properties of the material of the transition layers are characterized by low strength and low plasticity. In the structure of the intermetallic layers and at the boundary between them the formation of defects in the form of cracks and delaminations is observed.

Keywords: electron-beam additive technology, intermetallic composites, polymetals, gradient structures.

\section{Acknowledgment}

The work was performed according to the Government research assignment for the ISPMS SB RAS, project FWRW-2021-0012. 


\section{References}

1. Ghanavati R., Naffakh-Moosavy H. Additive manufacturing of functionally graded metallic materials: A review of experimental and numerical studies. Journal of Materials Research and Technology, 2021, vol. 13, pp. 1628-1664. DOI: 10.1016/j.jmrt.2021.05.022.

2. Panfilov A.O., Knyazhev E.O., Kalashnikova T.A., Kalashnikov Kirill. Manufacturing of $\mathrm{Cu}-\mathrm{Ni}$ and $\mathrm{Fe}-\mathrm{Cu}-\mathrm{Ni}$ polymetallic materials by the electron-beam additive technology. AIP Conference Proceedings, 2020, vol. 2310, pp. 020242. DOI: 10.1063/5.0034751.

3. Gurianov D.A., Kalashnikov K.N., Gusarova A.V., Chumaevskii Andrey V. Obtaining of the polymetallic samples from Ti-Al and Ti-Cu systems by the electron beam additive manufacturing method. AIP Conference Proceedings, 2019, vol. 2167, pp. 020126. DOI: 10.1063/1.5131993.

4. Chumaevskii Andrey V., Kalashnikov Kirill, Vorontsov Andrey, Zykova Anna. Evolution of microstructure and properties of $\mathrm{Fe}-\mathrm{Cu}$, manufactured by electron beam additive manufacturing with subsequent friction stir processing. Materials Letters, 2022, vol. 307, pp. 131023. DOI: $10.1016 /$ j.matlet.2021.131023.

5. Fernandez-Zelaia Patxi, Ledford Christopher, Ellis Elizabeth A.I., Campbell Quinn. Crystallographic texture evolution in electron beam melting additive manufacturing of pure Molybdenum. Materials \& Design, 2021, vol. 207, pp. 109809. DOI: 10.1016/j.matdes.2021.109809.

6. Afkhami S., Dabiri M., Habib Alavi S., Timo Björk. Fatigue characteristics of steels manufactured by selective laser melting. International Journal of Fatigue, 2019, vol. 122, pp. 72-83. DOI: $10.1016 /$ j.ijfatigue.2018.12.029.

7. Schopphoven T., Pirch N., Mann S. Statistical/Numerical Model of the Powder-Gas Jet for Extreme High-Speed Laser Material Deposition. Coatings, 2020, vol. 10, pp. 416. DOI: $10.3390 /$ coatings 10040416.

8. Zhang G., Xiong H., Yu H., Qin R.Y. Microstructure evolution and mechanical properties of wirefeed electron beam additive manufactured Ti-5Al-2Sn-2Zr-4Mo-4Cr alloy with different subtransus heat treatments. Materials \& Design, 2020, vol. 195, pp. 109063. DOI: 10.1016/j.matdes.2020.109063.

9. Xu Junqiang, Zhou Qi, Kong Jian, Peng Yong, Guo Shun, Zhu Jun, Fan Jikang. Solidification behavior and microstructure of Ti-(37-52) at\% Al alloys synthesized in situ via dualwire electron beam freeform fabrication. Additive Manufacturing, 2020, vol. 46, pp. 102113. DOI: 10.1016/j.addma.2021.102113.

10. Osipovich Kseniya, Chumaevskii Andrey V., Gusarova Anastasiya V., Kalashnikov Kirill. Mechanical properties of steel-copper polymetal manufactured by the wire-feed electron-beam additive technology. High Temperature Material Processes, 2020, vol. 24, pp. 91-98. DOI: 10.1615/HighTempMatProc.2020033790. 
Подана в журнал: 10.10 .2021

УДК 539.25:621.791.14:620.186.12

DOI: $10.17804 / 2410-9908.2021 .6 .019-031$

\title{
ПОЛУЧЕНИЕ ГРАДИЕНТНЫХ ИНТЕРМЕТАЛЛИДНЫХ СЛОЕВ НА ОСНОВЕ АЛЮМИНИЕВОГО СПЛАВА И МЕДИ МЕТОДОМ ЭЛЕКТРОННО-ЛУЧЕВОЙ АДДИТИВНОЙ ТЕХНОЛОГИИ
}

\author{
А. В. Чумаевский ${ }^{\mathrm{a}}{ }^{*}$, А. О. Панфилов ${ }^{\text {б) }}$, Е. О. Княжев ${ }^{\text {в) }}$, А. П. Зыкова ${ }^{\text {г) }}$, А. В. Гусарова ${ }^{\text {д) }}$,
} К. Н. Калашников ${ }^{\text {e) }}$, А. В. Воронцов ${ }^{\text {ж) }}$, Н. Л. Савченко ${ }^{3)}$, С. Ю. Никонов ${ }^{\text {и) }}$, А. М. Черемнов ${ }^{\text {к) }}$, В. Е. Рубцов ${ }^{\text {л) }}$, Е. А. Колубаев ${ }^{\text {м) }}$

Институт физики прочности и материаловедения Сибирского отделения Российской академии наук, пр. Академический 2/4, г. Томск, 634055, Российская Федераџия

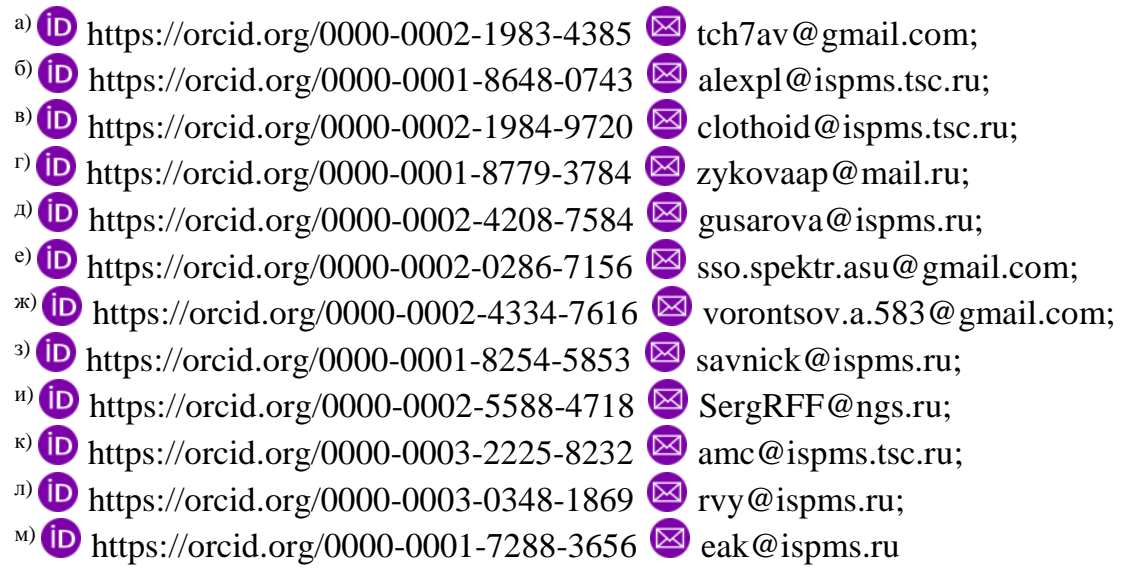

\author{
*Ответственный автор. Эл. почта: tch7av@gmail.com \\ Адрес для переписки: пр. Академический 2/4, г. Томск, 634055, Российская Федерация \\ Тел.: 8-961-891-41-49
}

В работе приведены результаты экспериментальной работы по получению и исследованию образцов полиметаллических слоистых изделий, полученных методом проволочной аддитивной электронно-лучевой технологии с использованием методики управляемой подачи филамента в ванну расплава. Полученные изделия на основе меди марки M1 и алюминиевого сплава АМг5 сочетают в структуре металлические и интерметаллидные слои с наличием градиентного перехода между ними. Внутри слоев с переходной структурой распределение интерметаллидных фаз может быть различного типа. Микротвердость различных структурных составляющих образцов различаются на величину, более чем в 16 раз. Механические свойства материала переходных слоев характеризуются невысокими значениями прочности и низкой пластичностью. В структуре интерметаллидных слоев и на границе между ними наблюдается формирование дефектов в виде трещин и расслоений.

Ключевые слова: электронно-лучевая аддитивная технология, интерметаллидные композиционные материалы, полиметаллы, градиентные структуры.

\section{1. Введение}

В настоящее время развитие технологий аддитивного производства позволяет существенно расширить номенклатуру выпускаемых изделий промышленного назначения с совмещением в одном изделии свойств двух и более различных разнородных материалов [1-4]. 
Одними из наиболее разработанных методик аддитивного производства изделий со сложной управляемой структурой являются селективное лазерное или электронно-лучевое сплавление (SLM, EBM) [5, 6], а также технологии направленного осаждения порошкового материала в струе газа (DED) [7]. Из технологий высокопроизводительного аддитивного производства наиболее широко представлена технология проволочного электроннолучевого производства (WAAM) [8]. Меньшее количество публикаций по данной теме можно выделить по электронно-лучевой аддитивной технологии (EBAM, EBF3) [4, 9]. При этом с точки зрения получения изделий с управляемой градиентной структурой поверхностного слоя данная технология имеет ряд преимуществ, заключающихся в возможности обеспечения плавного градиента от одного материала - к другому [10]. С помощью технологии электронно-лучевого производства возможно получение на поверхности печатаемого изделия твердых и прочных интерметаллидно-упрочненных поверхностных слоев с сохранением прочного и пластичного объема основного металла. Такие изделия могут иметь существенное значение для изготовления деталей трибологического назначения. При этом для получения деталей данным методом особое значение имеет методика подвода материала в ванну расплава, что требует проведения всесторонних исследований структуры и свойств материалов, полученных методом электронно-лучевого производства. Цель работы - исследование закономерностей организации структуры и свойств материала изделий на основе меди и алюминиевого сплава, полученных методом электроннолучевой технологии.

\section{2. Материал и методика}

Работы выполнены на экспериментальном оборудовании для аддитивной электронно-лучевой проволочной печати в Институте физики прочности и материаловедения СО РАН. Печать производилась по схеме, представленной на рис. 1. Вначале наносили на стальную подложку (сталь 12Х18Н9Т) чистую медь (марки М1) от одного источника проволоки (рис. 1 a). Количество слоев чистой меди состояло в пределах 10-15. Далее наносили слои градиентного слоя с постепенным увеличением содержания алюминия за счет печати одновременно двумя проволоками с постепенным увеличением подачи алюминиевого филамента (сплав АМг5) и снижением интенсивности подачи медной проволоки. Количество слоев градиентной зоны составляло от 15 до 20. В верхней части зоны структурного градиента интенсивности подачи двух проволок подбирали таким образом, чтобы материал состоял преимущественно из интерметаллидов. После получения экспериментальных образцов производилась вырезка металлографических шлифов и лопаток для механических испытаний на электроэрозионном станке DK7750. Определение механических свойств материала различных структурных зон образца проводили с использованием универсальной испытательной машины УТС 110М. Измерение микротвердости материала образцов выполнено на твердомере Duramin 5. Исследование структуры образцов после механической полировки и последующего травления образцов проводили на микроскопе Altami MET 1C и Olympus LEXT 4100. Рентгенофазовый анализ различных областей зоны структурного градиента выполнялся на рентгеновском дифрактометре ДРОН-7. 


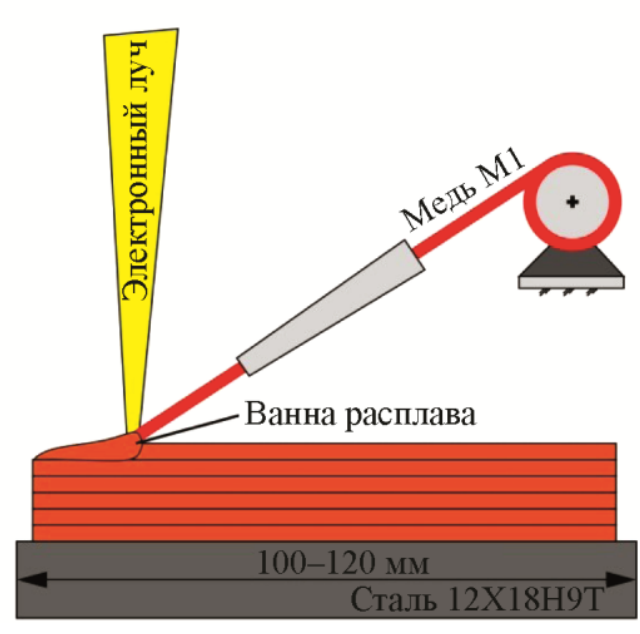

$a$

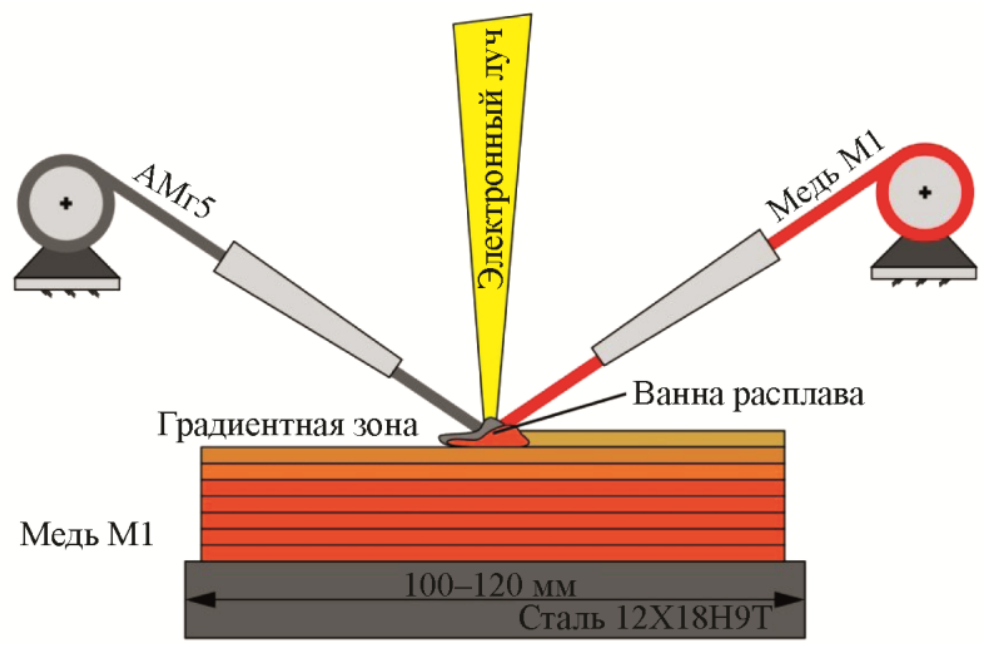

$\sigma$

Рис. 1. Схема процесса аддитивного электронно-лучевого проволочного получения образцов на основе меди и алюминиевого сплава АМг5: $a$ - схема процесса нанесения первых слоев чистой меди; $\sigma$ - схема процесса нанесения градиентного интерметаллидного слоя на основе алюминиевого сплава и меди

\section{3. Результаты и обсуждение}

Внешний вид типичного образца с градиентной структурой, полученных методом аддитивной электронно-лучевой проволочной технологии, представлен на рис. 2. На поверхности образцов формируются дефекты как поверхностного типа, так и распространяющиеся вглубь образца трещины или расслоения. При этом крупных дефектов обоих типов не образуется. Макроструктура образца в поперечном сечении представлена на рис. 3.

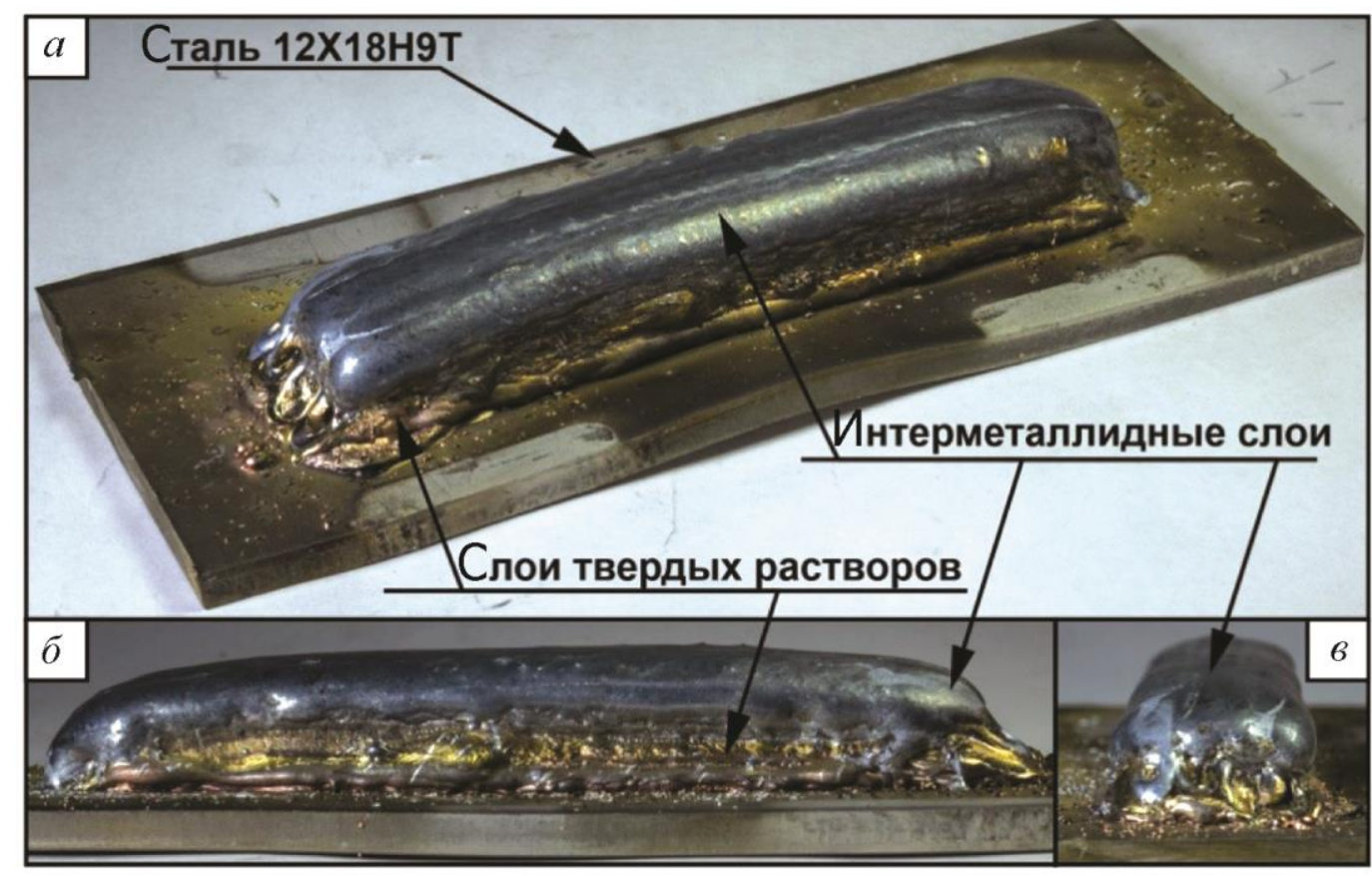

Рис. 2. Внешний вид образца после 3D-печати: $a$ - вид сверху; б - вид справа; в - вид спереди 


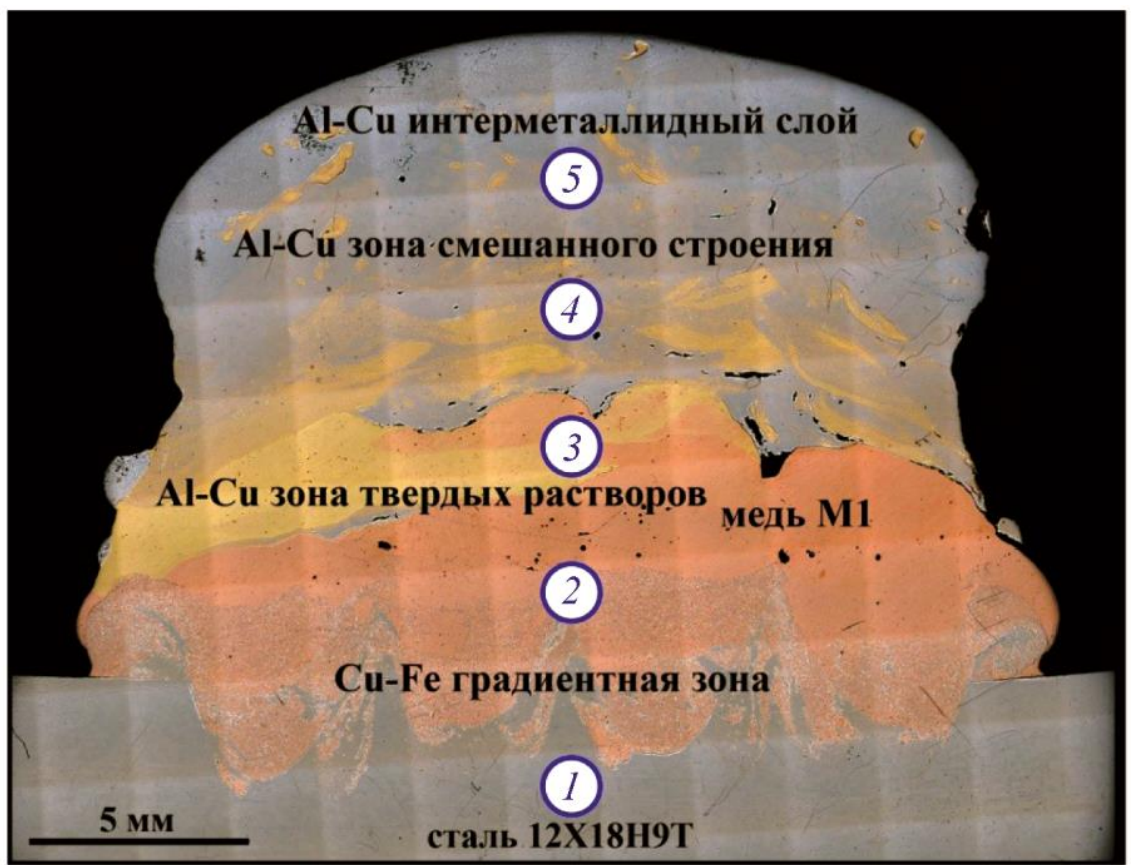

Рис. 3. Структура полученного образца в поперечном сечении

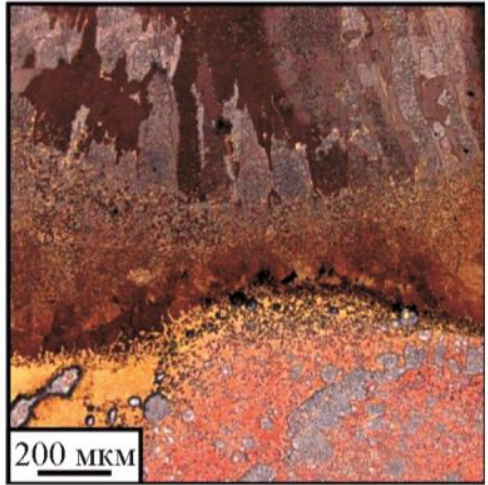

$a$

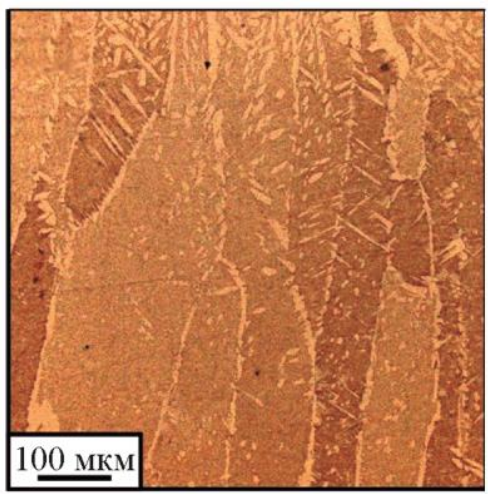

2

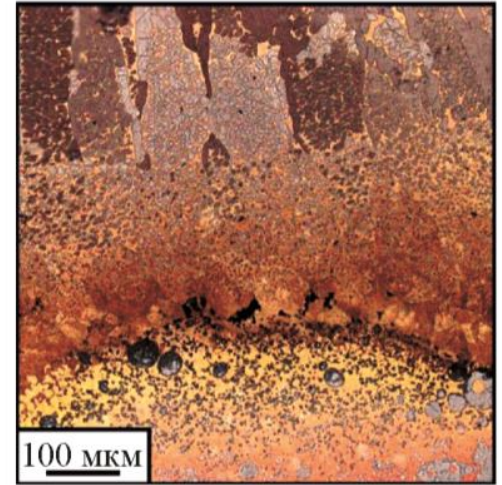

6

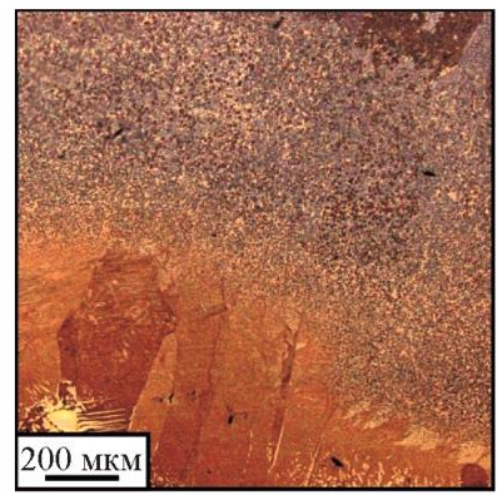

$\partial$

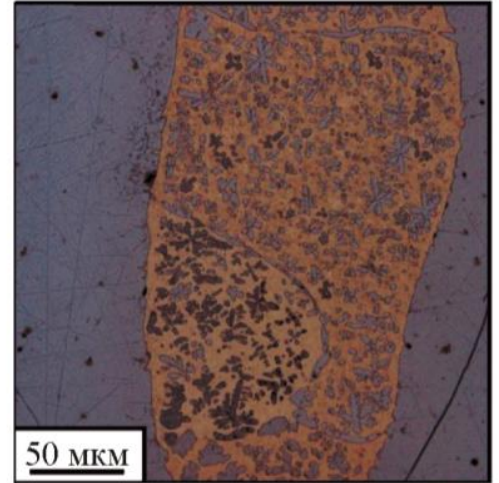

B

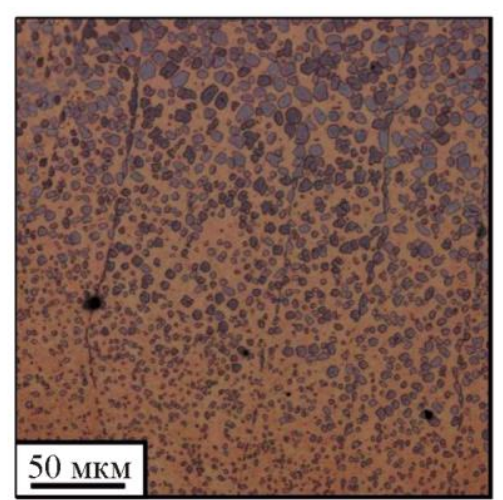

$e$

Рис. 4. Структура образца в поперечном сечении при большем увеличении. Зона переходной структуры от механической смеси меди и стали $(a, \sigma)$; зона с преимущественно интерметаллидной структурой (b); зона твердых растворов алюминия в меди (2) и зона смешанного строения на основе твердых растворов и интерметаллидных фаз $(\partial, e)$ 
Образец разделяется на несколько зон: зона стальной подложки (1), зона со структурой в виде механической смеси меди и стали (2), зона с преимущественной структурой в виде твердых растворов меди и алюминия (3), зона со смешанным строением на основе твердых растворов и интерметаллидных фаз (4) и зона с интерметаллидной структурой (5). На представленном изображении четко выделяется локализация образования крупных дефектов в виде трещин или расслоений, обусловленная отсутствием в правой части образца плавного перехода от твердого раствора на основе меди к интерметаллидным слоям. По причине существенных отличий в механических свойствах и значениях коэффициента термического расширения при остывании в данных областях происходит формирование дефектов. Макроструктура слоев, нанесенных на поверхность, имеет волнистое строение, обусловленное нанесением на подложку изначальных первых слоев. В областях с волнистой структурой внизу образца сталь от подложки может подниматься до первых слоев с твердорастворным типом фаз.

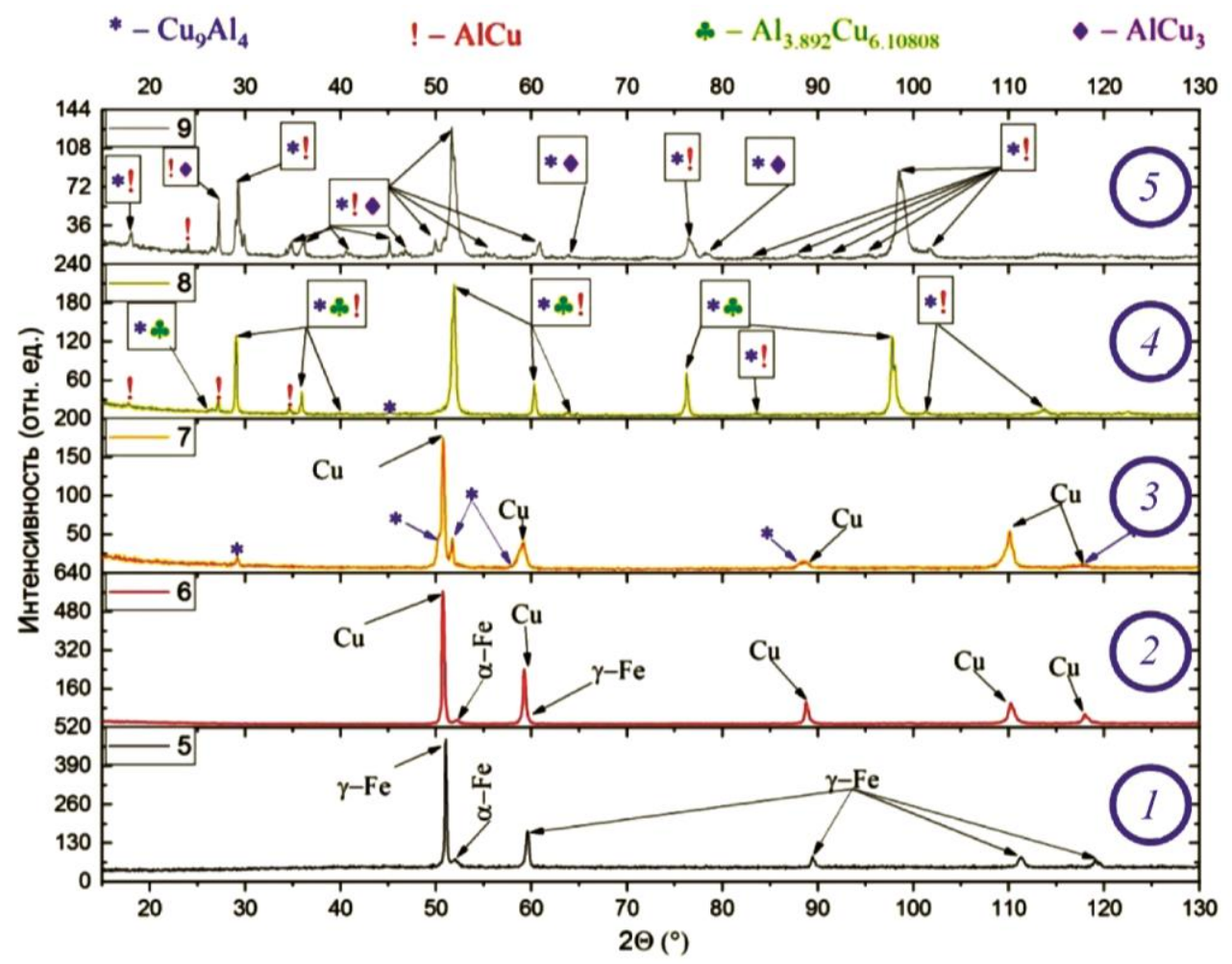

Рис. 5. Рентгенофазовый анализ основных структурных зон образцов, полученных в соответствии с изображением на рис. 3: 1 - подложка; 2 - переходная зона от подложки к медным слоям; 3 - зона преимущественного формирования твердых растворов на основе меди и алюминия; 4, 5 - зоны градиентных интерметаллидных слоев

При большем увеличении рассматриваемые структуры характеризуются сложным и неоднородным строением различных участков (рис. 4). В переходной зоне от области влияния подложки со смешанной структурой меди и стали - к зоне слоев твердых растворов меди и алюминия происходит образование переходных слоев с мелкодисперсной структурой с дальнейшим образованием столбчатых зерен (рис. $4 a$, б). Размер частиц интерметаллидов в областях смешанного строения может варьироваться от 1-2 мкм до крупных прослоек толщиной более 50-100 мкм (рис. 4 в). Внутри слоев с преимущественно твердорастворной структурой зерен в основном столбчатого типа (рис. 4 2), вытянутых в направлении отвода тепла при печати. При переходе к областям с интерметаллидным строением оптимальным является плавное повышение содержания мелких частиц интерметаллидов в матрице (рис. $4 \partial$ ). 
При таком соотношении компонентов не происходит образования трещин или расслоений в структуре образцов. Частицы интерметаллидов могут иметь форму как равноосных зерен (рис. 4 e), так и дендритную форму (рис. 4 в).

Результаты рентгенофазового анализа материала обозначенных выше структурных зон представлены на рис. 5. В зоне оплавленной подложки из аустенитной стали наблюдается структура на основе гамма-железа с остаточным дельта или альфа-ферритом (1). Выше структура представлена смесью альфа- и гамма-железа с чистой медью (2). В центральной зоне наблюдается образование твердых растворов меди и алюминия с образованием интерметаллидов $\mathrm{Cu}_{9} \mathrm{Al}_{4}(3)$. Выше располагаются слои с высоким содержанием интерметаллидных фаз различного состава $(4,5)$.

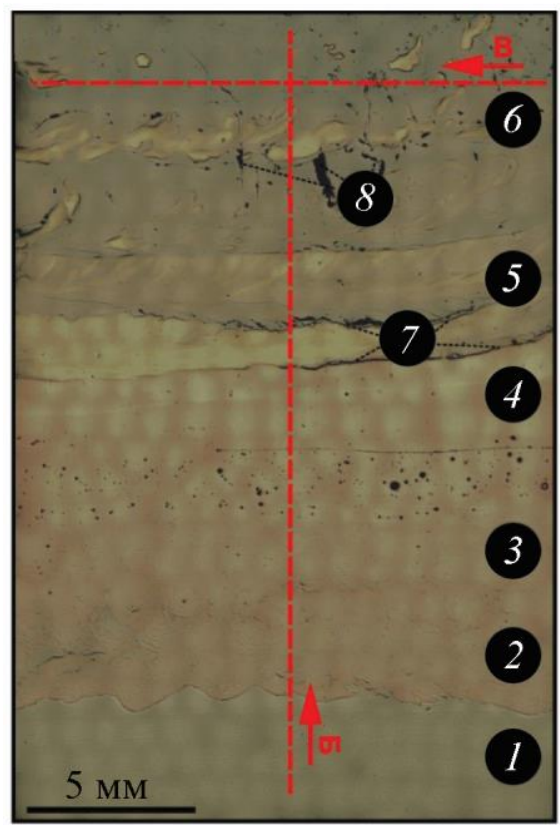

$a$

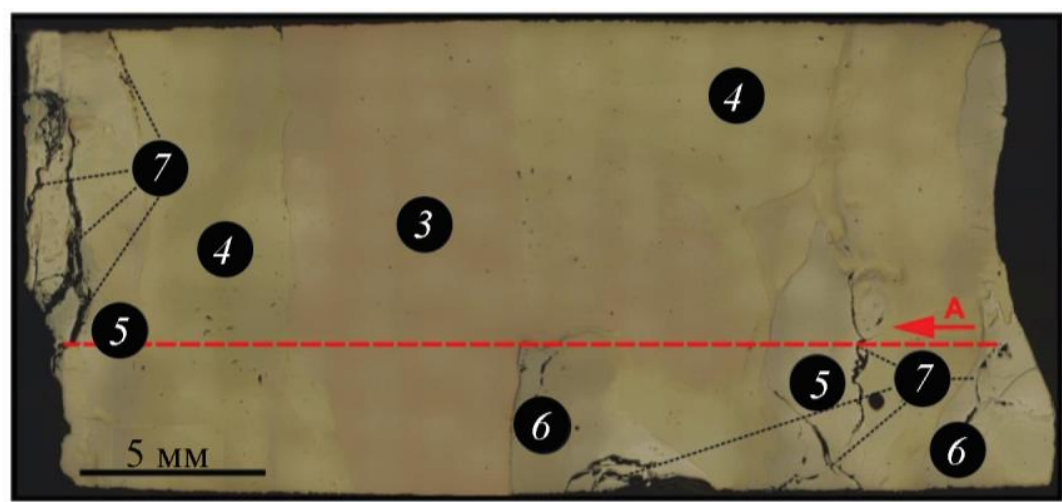

B

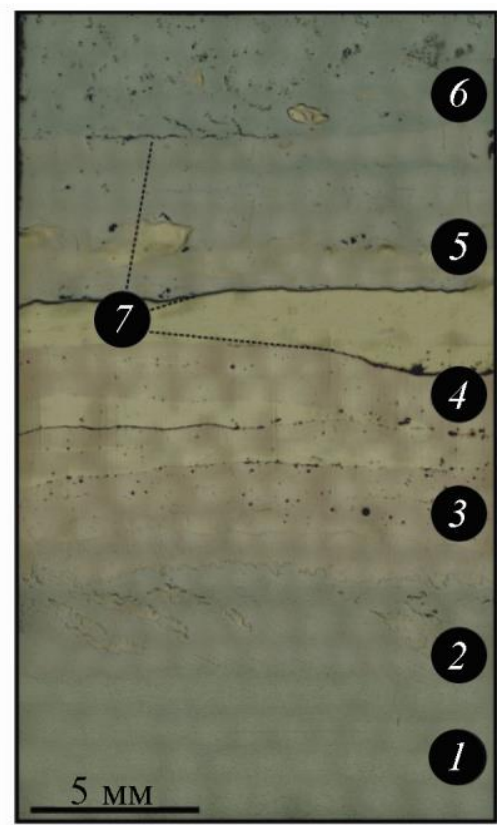

$\sigma$

Рис. 6. Макроструктура образца в продольном $(a, \sigma)$ и горизонтальном $($ в $)$ сечении

В продольном и горизонтальном сечениях структура образцов имеет существенные отличия от описанного ранее случая, основанные на процессе укладки слоев на поверхности (рис. 6). В продольном направлении структура образца неоднородна и значительно изменяется в различных участках (рис. $6 a$, б). При этом изменения в основном касаются размера 
и конфигурации слоев, а порядок их расположения остается неизменным в соответствии с заранее установленной структурой образца при печати.

Зона оплавленной подложки (1) (рис. $6 a$, б) расположена в нижней части образца и различается по толщине в виду зависимости от особенностей введения электронного пучка в материал, обуславловающих большую глубину оплавленного слоя в центре пучка. Зона смешанного состава из стали и меди образуется при нанесении первых слоев меди на оплавленную стальную подложку (2). Выше расположены слои нанесенной меди, в большом количестве содержащие дефекты в виде пор (3). При нанесении первых слоев смешанного состава на основе меди и алюминиевого сплава (4) в ряде участков образца формировались дефекты различного типа, но в основном граница между слоями является плавной. Далее располагаются слои со смешанной структурой с формирующимися интерметаллидными фазами и твердыми растворами (5), на границе между которыми и слоями с твердорастворным типом структуры возможно формирование трещин или расслоений (7). В верхней части образца формируются слои с интерметаллидным строением (6), содержащие в различных участках дефекты в виде пор или несплошностей (8).

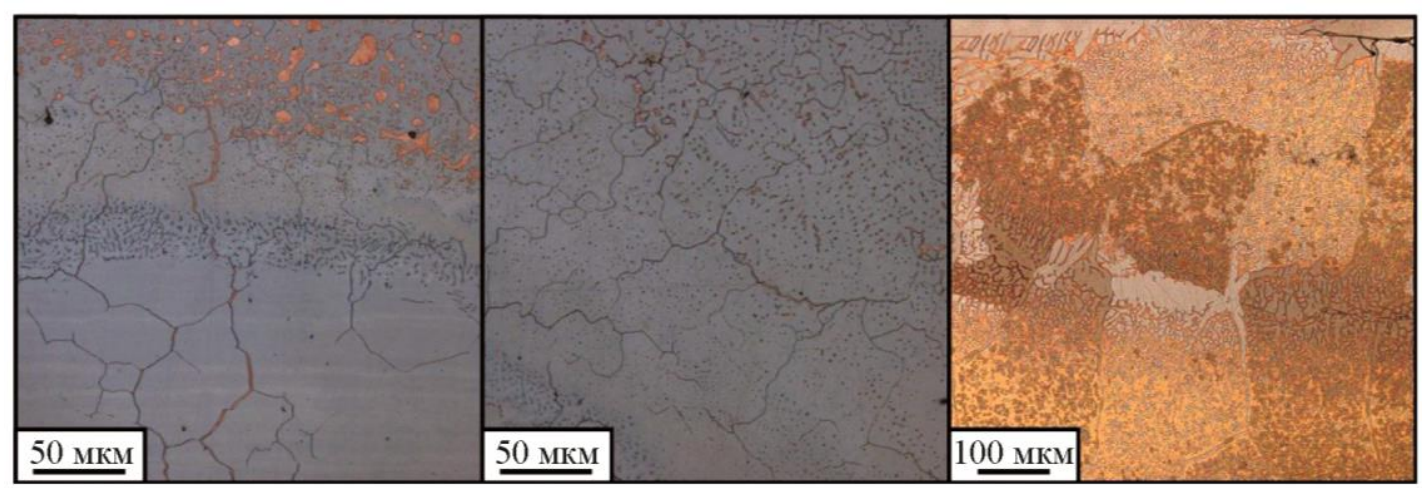

$a$

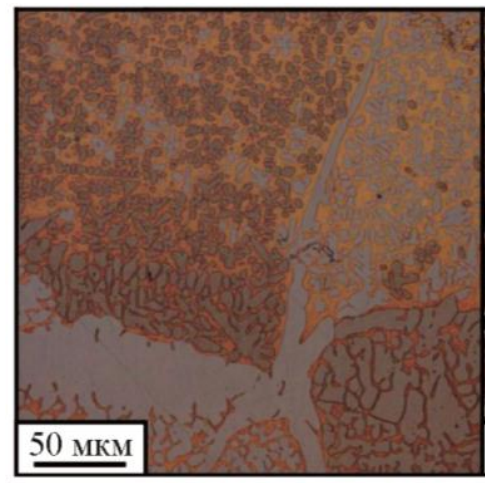

2 $\sigma$

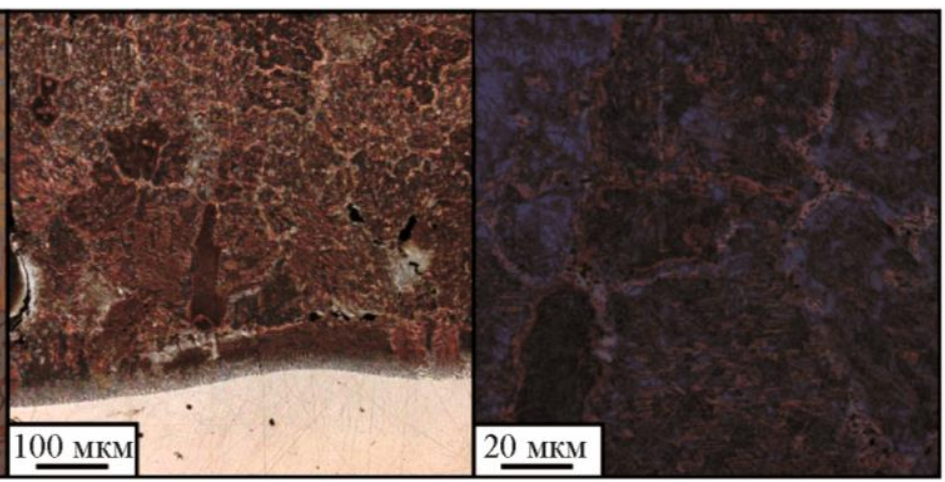

$\partial$

$e$

Рис. 7. Структура образца в продольном сечении при большем увеличении: переходная зона от подложки - к нанесенным слоям чистой меди $(a, \sigma)$; зона твердых растворов и интерметаллидных частиц $(6,2)$; области с интерметаллидной структурой $(\partial, e)$

При большем увеличении в образцах в приграничной зоне можно выделить наличие трещин в стальной подложке, заполненных медью и формирование сетчатых образований из меди в стальной матрице (рис. $7 a$, ). В областях смешанного строения могут образовываться сетчатые образования из интерметаллидных прослоек и частиц (рис. 7 в, г). В интерметал- 
лидных слоях также можно выделить как образование мелкодисперсных частиц второй фазы, распределенной в основе, так и протяженных прослоек (рис. $7 \partial, e$ ).

В горизонтальной плоскости структура в образцах также является достаточно неоднородной (рис. 6,8$)$. Несмотря на то, что в данном случае структура металла рассматривается внутри одного слоя, можно выделить существенную неоднородность строения с наличием зон со структурой чистой меди, твердорастворной, интерметаллидной и смешанной структурой. При большем увеличении можно выделить неоднородность строения переходных зон от чистой меди - к зоне твердых растворов (рис. $8 a$, б). В данном случае характерным является получение плавного перехода от меди - к однофазной зоне твердых растворов, а затем к протяженной граничной двухфазной области. Между интерметаллидными зонами и твердорастворными могут формироваться как резкие границы (рис. 8 в), так и протяженные переходные зоны (рис. 8 2). Строение зон смешанного состава представлено в основном смесью частиц интерметаллидных фаз различного состава и их агломераций внутри металлической матрицы, группирующихся в своеобразные ячейки (рис. $8 \partial, e$ ). Это указывает прежде всего на дендритный характер роста этих фаз в процессе кристаллизации с расположением осей дендритов перпендикулярно плоскости снимка, что в достаточной степени согласуется с представлениями о процессе плавления и кристаллизации материала при электроннолучевой проволочной 3D-печати.

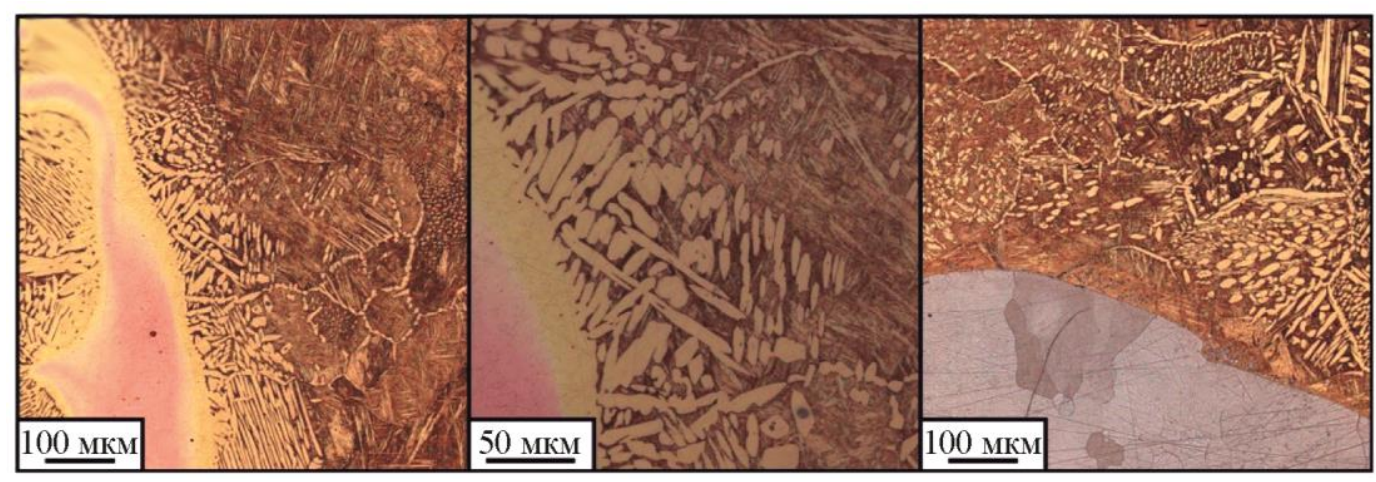

$a$

6

B

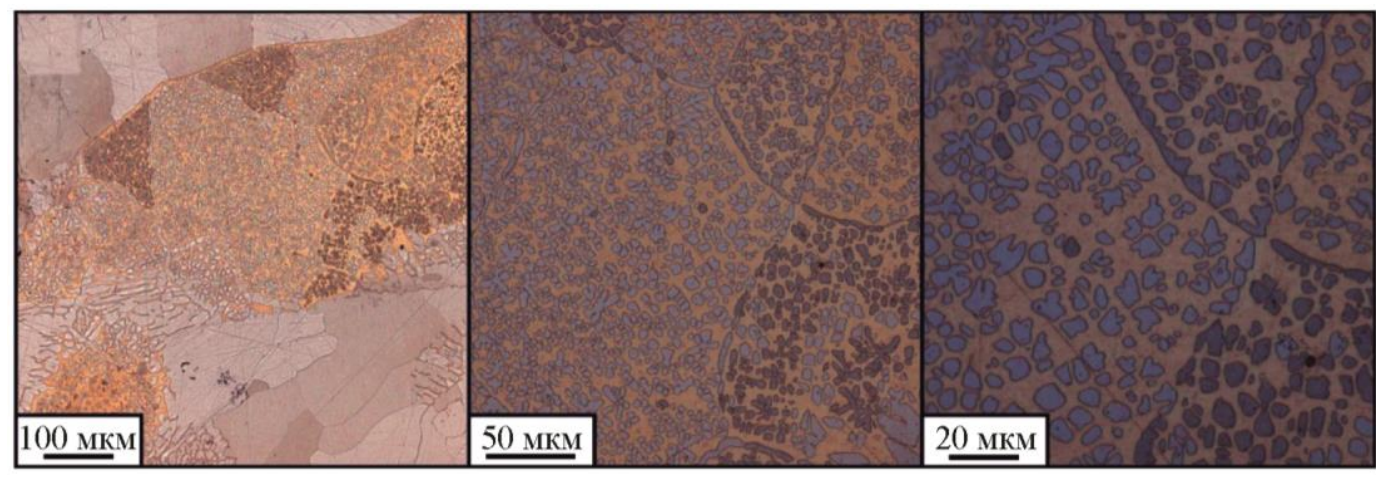

2

$\partial$

$e$

Рис. 8. Структура образца в горизонтальной плоскости при большем увеличении: зона смешанного строения $(a, \sigma)$; зона крупных частиц интерметаллидных фаз и твердых растворов $(6,2)$; зона с мелкодисперсным распределением интерметаллидов в твердом растворе алюминия в меди $(\partial, e)$ 
Полученные образцы помимо существенной неоднородности структуры обладают также и неоднородностями механических свойств. Изменение микротвердости образцов в вертикальном направлении (рис. $9 a$ ) характеризуется повышенными значениями твердости образцов в области вблизи подложки, снижением твердости в зоне медных слоев и резким ростом при переходе к интерметаллидным слоям. В поперечном направлении (рис. 9 б) в слое со смешанным строением можно выделить существенные различия в значениях микротвердости вдоль линии А, изображенной на рис. 6 в. В то время как максимальные значения микротвердости находятся на уровне 8 ГПа, минимальные могут составлять менее 0,5 ГПа. Минимальные значения микротвердости на графике соответствуют областям со структурой практически чистой меди, максимальные значения - областям с интерметаллидной структурой. Средние значения характерны для зон смешанного строения с содержанием интерметаллидных частиц в металлической матрице и обусловлены тем, что индентор может захватывать как матрицу, так и частицы интерметаллидов. В продольном направлении изменение микротвердости внутри интерметаллидных слоев в верхней части образца также представляется достаточно неоднородным, хотя и наблюдается группировка значений вокруг среднего (рис. 9 в).

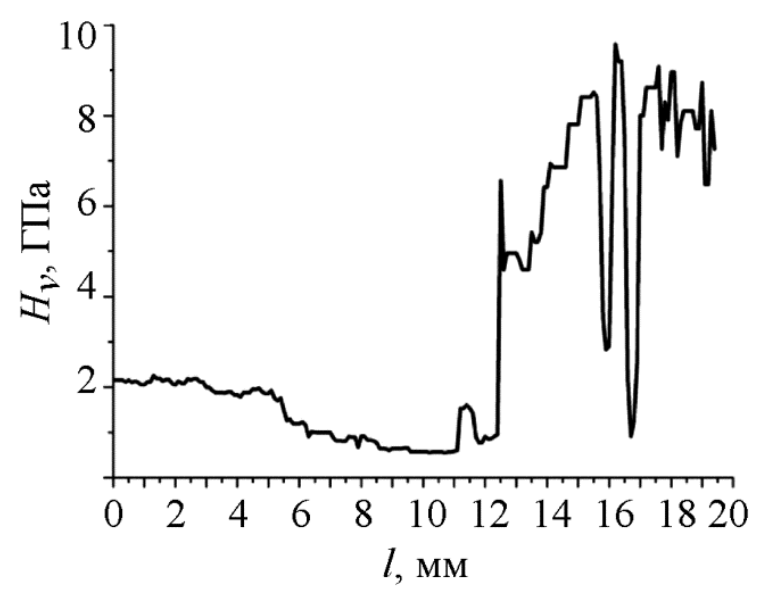

$a$

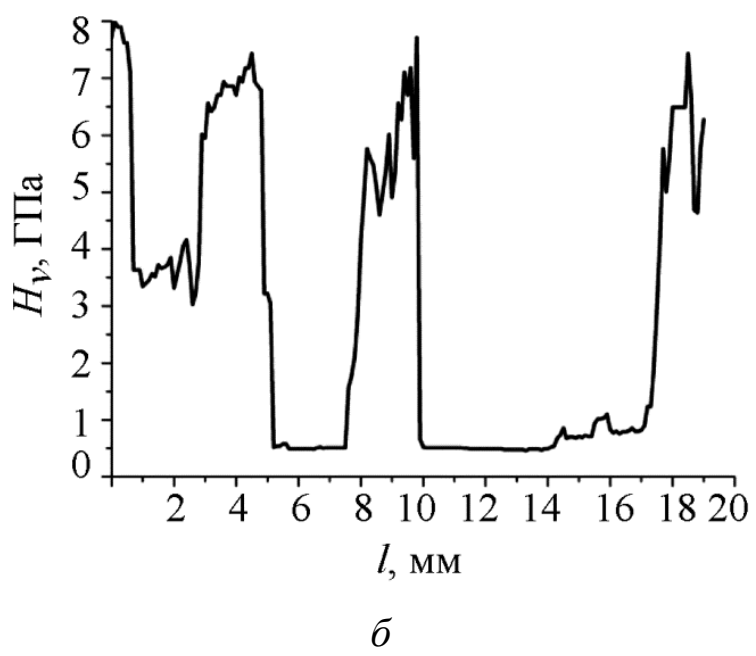

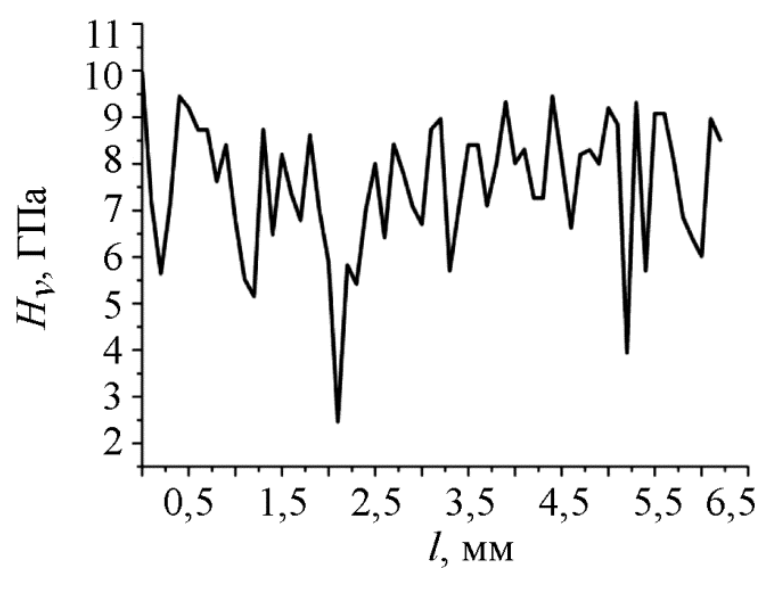

B

Рис. 9. Изменение микротвердости в образце: в продольном $(a)$; вертикальном (б) и поперечном (в) направлениях

Значения прочностных свойств образцов также характеризуются существенным разбросом значений параметра временного сопротивления от прочности чистой меди 145-200 МПа до прочности механической смеси меди и стали близи подложки 340-350 МПа. Пластич- 
ность таких образцов находится в пределах 25-30 \%. Предел текучести медных слоев составляет 100-110 МПа, областей смешанного строения из меди и стали 190-210 МПа.

Прочностные свойства зон интерметаллидного строения из-за образования дефектов в виде трещин или расслоений достаточно невелики. Временное сопротивление различных участков данных слоев находится в пределах от 100 до $170 \mathrm{MПа,} \mathrm{при} \mathrm{этом} \mathrm{пластичность} \mathrm{ма-}$ териала даже в областях со смешанной композитной структурой может быть 4-5 \% и ниже, а в областях с интерметаллидным строением разрушение происходит практически без пластической деформации. Предел текучести данных участков составляет от 60 до 170 МПа.

\section{4. Заключение}

Проведенные исследования показывают, что в процессе проволочной электроннолучевой аддитивной 3D-печати происходит образование сложноорганизованной слоистой структуры с заданным структурно-фазовым состоянием отдельных слоев. Полученный материал имеет структуру, изменяющуюся от механической смеси частиц стали и медной матрицы вблизи подложки, твердых растворов меди и алюминия в центральных объемах к интерметаллидным структурам в поверхностном слое. С использованием электронно-лучевой технологии получены образцы на основе меди и алюминия с повышенной в 16 раз твердостью поверхностных слоев. Несмотря на повышенные показатели по твердости материала поверхностных слоев ввиду образования ряда дефектов различного типа, механические свойства материала поверхностных слоев находятся на достаточно низком уровне, хотя и могут быть приемлемыми при эксплуатации. Основные причины образования дефектов заключаются в нестабильности процесса печати и формировании резких границ между интерметаллидными крупными частицами, прослойками или слоями. Образование трещин в данном случае ожидаемо по причине существенных различий в значениях коэффициента теплового расширения меди, твердых растворов на основе меди и алюминия и интерметаллидных фаз различного состава $\left(\mathrm{AlCu}_{3}, \mathrm{Al}_{2} \mathrm{Cu}_{3}, \mathrm{AlCu}, \mathrm{Cu}_{9} \mathrm{Al}_{4}\right.$ и др.). Дополнительно образование трещин и отслоений обусловлено низкими значениями пластичности интерметаллидных фаз. В работе установлено также, что при образовании протяженных градиентных переходных зон от меди - к интерметаллидным слоям трещин и отслоений не формируется, что свидетельствует о необходимости управления процессом печати таким образом, чтобы избегать резких границ между соседними разнородными областями. По этой причине в дальнейшем планируется увеличение стабильности подвода материала в зону печати и увеличение плавности градиента от слоев с твердорастворным типом фаз к слоям с интерметаллидной структурой.

\section{Благодарность}

Работа выполнена в рамках государственного задания ИФПМ СО РАН, тема номер FWRW-2021-0012.

\section{Литература}

1. Ghanavati R., Naffakh-Moosavy H. Additive manufacturing of functionally graded metallic materials: A review of experimental and numerical studies // Journal of Materials Research and Technology. - 2021. - Vol. 13. - P. 1628-1664. - DOI: 10.1016/j.jmrt.2021.05.022.

2. Manufacturing of $\mathrm{Cu}-\mathrm{Ni}$ and $\mathrm{Fe}-\mathrm{Cu}-\mathrm{Ni}$ polymetallic materials by the electron-beam additive technology / A. O. Panfilov, E. O. Knyazhev, T. A. Kalashnikova, Kirill Kalashnikov // AIP Conference Proceedings. - 2020. - Vol. 2310. - P. 020242. - DOI: 10.1063/5.0034751.

3. Obtaining of the polymetallic samples from $\mathrm{Ti}-\mathrm{Al}$ and $\mathrm{Ti}-\mathrm{Cu}$ systems by the electron beam additive manufacturing method / D. A. Gurianov, K. N. Kalashnikov, A. V. Gusarova, 
Andrey V. Chumaevskii // AIP Conference Proceedings. - 2019. - Vol. 2167. - P. 020126 DOI: $10.1063 / 1.5131993$.

4. Evolution of microstructure and properties of $\mathrm{Fe}-\mathrm{Cu}$, manufactured by electron beam additive manufacturing with subsequent friction stir processing / Andrey V. Chumaevskii, Kirill Kalashnikov, Andrey Vorontsov, Anna Zykova // Materials Letters. - 2022. - Vol. 307. - P. 131023. DOI: $10.1016 /$ j.matlet.2021.131023.

5. Crystallographic texture evolution in electron beam melting additive manufacturing of pure Molybdenum / Patxi Fernandez-Zelaia, Christopher Ledford, Elizabeth A.I. Ellis, Quinn Campbell // Materials \& Design. - 2021. - Vol. 207. - P. 109809. - DOI: 10.1016/j.matdes.2021.109809.

6. Fatigue characteristics of steels manufactured by selective laser melting / S. Afkhami, M. Dabiri, S. Habib Alavi, Björk Timo // International Journal of Fatigue. - 2019. - Vol. 122. P. 72-83. - DOI: 10.1016/j.ijfatigue.2018.12.029.

7. Schopphoven T., Pirch N., Mann S. Statistical/Numerical Model of the Powder-Gas Jet for Extreme High-Speed Laser Material Deposition // Coatings. - 2020. - Vol. 10. - P. 416. DOI: $10.3390 /$ coatings10040416.

8. Microstructure evolution and mechanical properties of wire-feed electron beam additive manufactured Ti-5Al-2Sn-2Zr-4Mo-4Cr alloy with different subtransus heat treatments / G. Zhang, H. Xiong, H. Yu, R. Y. Qin // Materials \& Design. - 2020. - Vol. 195. - P. 109063. DOI: 10.1016/j.matdes.2020.109063.

9. Solidification behavior and microstructure of Ti-(37-52) at $\%$ Al alloys synthesized in situ via dual-wire electron beam freeform fabrication / Junqiang Xu, Qi Zhou, Jian Kong, Yong Peng, Shun Guo, Jun Zhu, Jikang Fan // Additive Manufacturing. - 2020. - Vol. 46. - P. 102113. DOI: 10.1016/j.addma.2021.102113.

10. Mechanical properties of steel-copper polymetal manufactured by the wire-feed electronbeam additive technology / Kseniya Osipovich, Andrey V. Chumaevskii, Anastasiya V. Gusarova, Kirill Kalashnikov // High Temperature Material Processes. - 2020. - Vol. 24. - P. 91-98. DOI: 10.1615/HighTempMatProc.2020033790. 